\title{
Strength Analysis of Jacket Platform Based on ANSYS
}

\author{
REN Hongwei \\ Drilling Technology Research Institute, Dongying \\ renhw_123@163.com
}

Key words: jacket platform, strength analysis, current load, PIPE59 element.

Abstract. The wave force analysis of jacket platform is hard in the design. PIPE59 element in ANSYS software has the function of computing buoyancy, wave and current load. By control the unit parameters, can simulate current load automatically. In the Water Table menu input eight direction wave flow parameters respectively. Fatigue analysis needs the maximum and minimum of wave load in a cycle of platform, programming to calculate the phase angle of maximum effect in each direction. By modeling analysis, the structural displacement and stress at various points of jacket is obtained in eight kinds of conditions.

\section{Introduction}

In the actual platform design, according to the different area, select different wave theory to calculate the wave forces acting on the structure. Algorithm for two-dimensional wave theory has been a lot of research and application, but in terms of domestic large platform structure analysis system still has a lot of work to be solved [1,2]. In modern platform design, with artificial to simplify the effect on the structure of wave load has been impractical, so to solve large jacket platform structure analysis of wave load automatic processing problem has practical significance.

\section{PIPE59 element}

\section{Element characteristics}

PIPE59 unit in the ANSYS software is unit, similar to that of the space beam element to calculate fluid static and dynamic effect of circular tubular components [3]. Consider the axial tension and compression, torsion and bending deformation, on the basis of the general beam element expansion of the buoyancy of the unit, wave and current load calculation function. Use of these characteristics, consider using analog current load, the unit by unit control input parameters, can automatically simulate current characteristics, and calculates the current load.

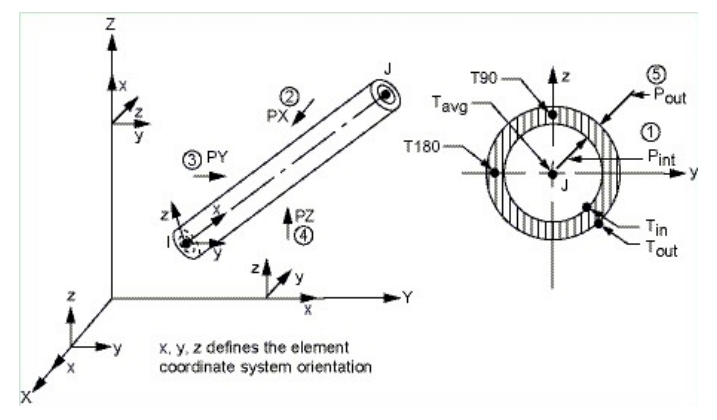

Fig. 1 PIPE59 element model

PIPE59 element of each node were six degrees of freedom, namely along the $\mathrm{x}, \mathrm{y}, \mathrm{z}$ direction of the line displacement and around the $\mathrm{x}, \mathrm{y}, \mathrm{z}$ axis of the angular displacement (see figure 1). 
Unit input data include two nodes, pipe diameter, wall thickness as well as some information load and inertia; Isotropic material properties; External attachments (including ice load and biological attachment); Material used to calculate the external fluid viscous coefficient of Renault coefficient [4]. $X$ axis direction of the unit for the node to node $\mathrm{j}$, I parallel to the $\mathrm{y}$ direction according to the $\mathrm{x}-\mathrm{y}$ plane automatic calculation. In the case of parallel unit and $\mathrm{z}$ axis (or slope within $0.01 \%$ ), unit of $y$ axis parallel with the overall coordinate in the direction of the $y$ axis. Are thought to have zero unit of input or output of the external environment along the y axis, and 90 degrees of unit of input or output of the external environment along the $\mathrm{z}$ axis distribution is similar.

\section{Simulate current load through the Water Table}

Jacket platform structure finite element analysis, to support structure with mud surface above PIPE59 element simulation; for mud surface in the following sections the PIPE16 unit simulation.

Because the jacket is fixed, the water flow, fluid power may be produced. Fluid motion has two aspects, wave and flow movement. By giving eight different vertical location of the velocity and direction to the input stream [5]. Speed and direction of a linear interpolation between these location. Waves through the TBDATA command input, waveform from four kinds of wave theory in a choice of the input. Choose the stokes theory calculation example, the design depth of $18 \mathrm{~m}$, check high water level of $3.5 \mathrm{~m}$, velocity of $1.03 \mathrm{~m} / \mathrm{s}$, direction of $0^{\circ} 、 45^{\circ} 、 90^{\circ} 、 135^{\circ} 、 180^{\circ} 、 225^{\circ} 、 270^{\circ}$ 、 $315^{\circ}$, wave $6.7 \mathrm{~m}$, cycle $9 \mathrm{~s}$.

Waves through the jacket platform, as the change of seismic phase periodic, the force of platform structure are also being cyclical changes. In load calculation, need to consider the wave, wave direction, wave frequency and other factors. In addition, the fatigue analysis of platform in a cycle is one of the biggest, the smallest wave loads. Therefore according to certain step length of phase Angle $\left(0 \sim 360^{\circ}\right)$ were equal, equinoctial platforms such as calculation in each phase is obtained by the wave load, access to the joint effort of the maximum and minimum calculation results, the fatigue analysis of working condition of load calculation. Programming environment load calculation obtained from eight directions applying phase Angle to produce the most of each direction, the calculation results are shown in table 1.

Table 1 Phase Angle calculation results

\begin{tabular}{lcccccccc}
\hline Direction of the load & $0^{\circ}$ & $45^{\circ}$ & $90^{\circ}$ & $135^{\circ}$ & $180^{\circ}$ & $225^{\circ}$ & $270^{\circ}$ & $315^{\circ}$ \\
Phase Angle & $350^{\circ}$ & $336^{\circ}$ & $342^{\circ}$ & $4^{\circ}$ & $28^{\circ}$ & $41^{\circ}$ & $36^{\circ}$ & $14^{\circ}$ \\
\hline
\end{tabular}

Input wave flow parameters through the Material Models menu of Water Table (see figure 2), automatic simulation wave load flow calculation.

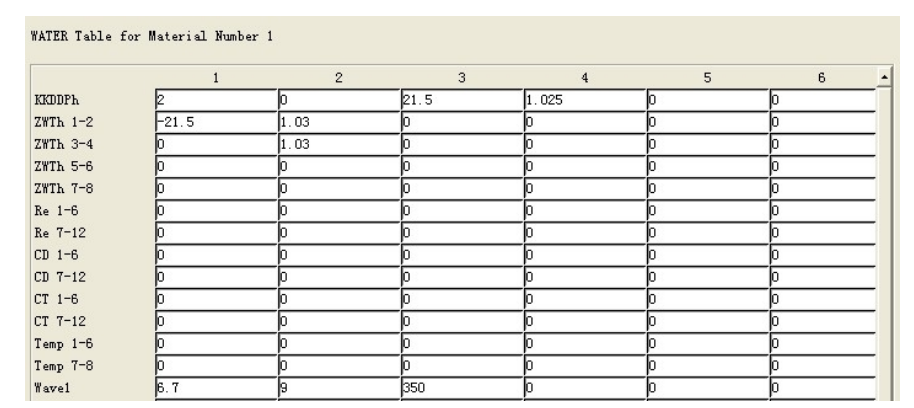

Fig. 2 Input wave flow parameters 


\section{Jacket platform strength analysis}

\section{Structure calculation model}

Using ANSYS software to build the finite element model, take deck grillage and jacket of main girder (including pile in the ducts and pipes as compound cross section) of each component as a beam element space structure. Use PIPE59 and PIPE16 element model jacket, and BEAM element simulation platform grillage model. Model has 598 units and 527 nodes. Modeling of should consider to place a breakpoint on surface of the mud, mud under the surface model assignment of different unit.

According to the specification, the bottom of the pile can be modeled by a rigid fixed end, rigid fixed end below the design mud surface vertical $\mathrm{T}(\mathrm{m})$ [6]. Design on the surface of the mud position under natural mud surface distance should be decided according to the geological conditions. T value is decided according to the empirical formula.

$$
T=6 \mathrm{D} \text { 。 }
$$

Type: $\mathrm{D}$ - the pile diameter, $\mathrm{m}$.

\section{Combination condition analysis}

\section{Ice load}

Under the action of wind and current, large ice sheet extrusion of the ice load produced by the vertical isolation pile and the calculation method of maximum ice force of the jacket are:

$$
F_{l}=m \times K_{1} \times K_{2} \times \sigma_{c} \times D \times h
$$

Type: K1, K2 - the local extrusion coefficient of pile and pile with ice contact coefficient; $M$ - the shape coefficient of pile, garden cylinder to take $0.9 ; \sigma_{c}$ - the uniaxial compressive strength limit of ice (KPa), $2244 \mathrm{KPa}$. D - jacket diameter (m); H - ice thickness (m).

\section{The wind load}

Direction of maximum wind speed of $45 \mathrm{~m} / \mathrm{s}, 0^{\circ} 、 45^{\circ} 、 90^{\circ} 、 135^{\circ} 、 180^{\circ} 、 225^{\circ} 、 270^{\circ} 、 315$ ${ }^{\circ}$. Wind load calculation formula is:

$$
F_{w}=K \times K_{z} \times p_{0} \times A
$$

Type: $p_{0}$ - basic wind pressure; K- shape coefficient; Kz - sea wind pressure height coefficient of change; A - structures by the projected area of the wind. weight of the deck and equipment load and live load load according to actual situation.

\section{The results of the analysis}

Using ANSYS structural analysis software for structural static analysis to the above conditions, available at various points within the structure displacement and the fourth strength theory (Mises) equivalent stress. Platform components under the action of external loading should have sufficient strength and stiffness, according to the structure static analysis, each component of the internal force are obtained. According to security conditions, according to the specification corresponding formulae for checking.

Platform jacket and pile are calculated according to the requirements of the strength of the pipe component and formula, when the stress of the component for the axial tension or compression, and in two in-plane bending, the strength checking formula is:

$$
\sigma_{\max }=\frac{N}{A} \pm 0.9 \frac{\sqrt{M_{x}^{2}+M_{y}^{2}}}{W} \leq[\sigma]
$$

Type: $\sigma_{\max }-$ working stress; $\mathrm{N}$ - calculating section axial force; Mx, My - calculating section respectively around the $\mathrm{x}$ and $\mathrm{y}$ axis bending moment; $\mathrm{A}$ - component of section area; $\mathrm{W}$ - component 
section modulus; $[\sigma]$ - allowable stress of material, for tensile, compressive and bending, allowable stress $[\sigma]=0.8 \sigma_{s}$.

Mises stress at various points structure as shown in figure 3, through the calculation analysis shows that the ice load, flow load and wind load along the $225^{\circ}$ incidence Angle, the most dangerous of the platform structure, platform deck part of maximum working stress is $139.8 \mathrm{MPa}$, jacket and effect in the part of the maximum working stress is $99.8 \mathrm{MPa}$. The maximal displacement appears on the top of the platform; its displacement is $2.4 \mathrm{~cm}$.

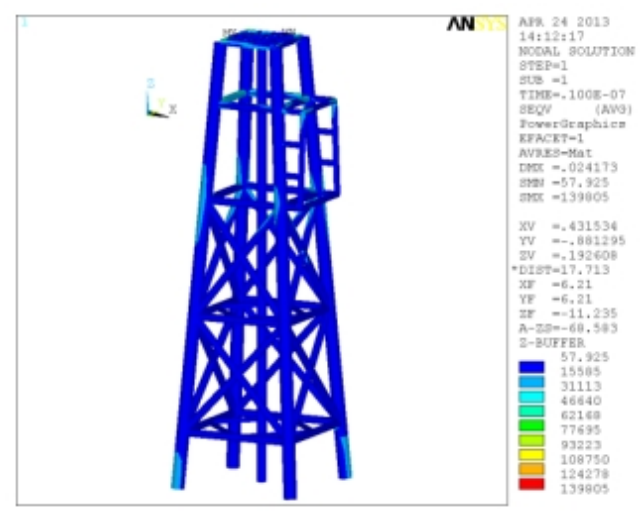

Fig. 3 Platform load stress nephogram with $225^{\circ}$ Angle

\section{Conclusions}

(1) according to certain step length equal to phase Angle, equinoctial platforms such as programming calculation in each phase is obtained by the wave load, access to the joint effort of the maximum and minimum calculation results, the fatigue analysis of working condition of load calculation. Control wave flow parameters through the Water Table menu.

(2) Through the load modeling analysis, we get eight kinds of the structure under the condition of Mises stress at every point, and calculate the ice load, flow load and wind load along the $225^{\circ}$ incidence Angle, the platform structure is the most dangerous.

\section{Reference}

[1] Zheng Xuekun, Chen Yihou, Wang Song. Jacket offshore wave seismic load analysis and research[J]. Inner Mongolia petrochemical industry, 2007, (5): 321-322.

[2] Jiang Shaoyun, etc. Under the action of wave flow jacket platform pile foundation scour experiment research[J]. Petroleum machinery, 2012,40 (9): 57-61.

[3] Gao Chang. Jack-up platform truss legs wave load flow analysis and experimental research[D]. Tianjin: Tianjin university, 2010.

[4] Zhang Dongsheng, etc. The static finite element analysis of pressure tank[J]. Mechanical design and manufacturing, 2013, (2): 45-47.

[5] Qin Yu. ANSYS based tutorial and examples[M]. Beijing: Chemical industry press.

[6] China classification society, Rules for the classification and construction of offshore fixed platform [M], Beijing: China Communications Press, 1992. 